\title{
DERMEVAL SAVIANI: ESBOÇO DE UM CRÍTICO EDUCADOR BRASILEIRO
}

\section{ARTIGO ORIGINAL}

GODOY, Juliano Bernardino de ${ }^{1}$

ASSIS, Rogério de ${ }^{2}$

GODOY, Juliano Bernardino de. ASSIS, Rogério de. Dermeval Saviani: Esboço de um crítico educador brasileiro. Revista Científica Multidisciplinar Núcleo do Conhecimento. Ano 05, Ed. 05, Vol. 07, pp. 116-126. Maio de 2020. ISSN: 2448-0959,

1 Doutorando em Educação na Universidade Metodista de Piracicaba (UNIMEP). Mestre em Educação pela Universidade Metodista de Piracicaba (UNIMEP) 2019; Linhas de Pesquisa, História e Filosofia da Educação. Licenciado em História pela UNIESP 2012. Licenciado em Bacharel em Filosofia pelo Centro Universitário Claretiano 2014/2019 (CLARETIANO). Bacharel em Teologia pelo Centro Universitário Claretiano (CLARETIANO) 2015. Licenciado em Pedagogia pelo Centro Universitário de Araras (UNAR) 2016. Licenciado em Sociologia pelo Centro Universitário de Araras (UNAR) 2018. Licenciado em Geografia a pelo Centro Universitário de Araras (UNAR) 2020.

2 Mestrado em Educação pela Universidade Nove de Julho (UNINOVE), 2019; Linha de pesquisa: Educação, Filosofia e Formação Humana (LIPEFH), integrante do Grupo de Pesquisa e Estudo em Filosofia da Educação - (GRUPEFE) e Grupo de Pesquisa e Estudo da Complexidade (GRUPEC), sob a coordenação dos Profs. Dr. Antônio Joaquim Severino e Dra. Cleide Rita Silvério de Almeida (UNINOVE). Pós-Graduação Lato Sensu em Formação de Docentes para o Ensino Superior pelo Centro Universitário Assunção (UNIFAI) 2015; Pós-Graduação em Teologia Reformada pela Missão Evangélica Literária (CFL) 2019; Bacharelado em Teologia pela Pontifícia Faculdade de Teologia Nossa Senhora da Assunção - Centro Universitário Assunção (UNIFAI) 2007; Bacharelado em Teologia pelo Instituto Anglicano de Estudos Teológicos (IAET) 2005. 
Link de acesso: https://www.nucleodoconhecimento.com.br/educacao/dermeval$\underline{\text { saviani }}$

\section{RESUMO}

Trata o presente artigo da vida e obra do educador brasileiro Dermeval Saviani, ainda vivo e nascido no interior de São Paulo, Brasil. De família humilde, Dermeval se destacou com os seus estudos, tanto no Brasil quanto no exterior, sendo conhecido e reverenciado pelos educadores pela sua contribuição e pensamento crítico. Teria o filósofo e educador brasileiro Dermeval Saviani algo a dizer aos estudantes e educadores dos dias atuais, ou, ao conhecê-lo, encontra-se apenas um modelo educacional que faz parte do passado? A fim de atingir o objetivo proposto, foi estudada a sua biografia, obras e a sua pedagogia histórico-crítica, chegando-se, portanto, às considerações finais. Procurou-se demonstrar, de forma suscinta, que muito mais do que conhecer o pensamento deste educador, é reconhecer que tal pensamento e crítica de forma alguma faz parte do acervo cultural educacional do passado, mas, muito pelo contrário, tal pensamento está muito vivo, tal qual o próprio pensador e, portanto, lança luz na realidade educacional brasileira dos dias atuais como um formador de opinião.

Palavras-chave: Dermeval Saviani, filosofia brasileira, educação.

\section{INTRODUÇÃO}

Conhecer a vida e a obra de Dermeval Saviani é conhecer a vida e a obra de um homem simples e do campo que, ao contrário de seus pais apenas alfabetizados, destacou-se com seus estudos, chegando a estudar nas melhores universidades brasileiras e no exterior. Muito mais do que isso, é conhecer a vida e obra de alguém que se destacou deixando a todos os seus leitores (as), de modo especial aos educadores (as), um legado de um pensamento atualíssimo sobre a realidade da educação brasileira. O presente artigo está dividido nas seguintes seções: biografia, obras, pedagogia histórico-crítica, considerações finais e referências. Claro que todo 
o artigo tem a sua importância, mas acredita-se que a parte mais relevante seja a pedagogia histórico crítica.

Frente aos imensos desafios educacionais pelos quais o Brasil tem passado, o pensamento de Saviani desvela-se atual e ainda perigoso, desafiador. Perigoso e desafiador pelo simples fato de ser crítico. Crítica esta que o leitor (a) sabe, embora faça parte do discurso educacional, nem sempre foi bem visto, nem no passado, nem no presente. Irá nos dizer Saviani que quando se vive tempos de curvatura da vara e aqui pode-se pensar nos inúmeros movimentos educacionais atuais e tradicionais ou tradicionalistas, como, por exemplo, escola sem partido, não adianta simplesmente deixar a vara quieta para que ela se endireite, muito mais do que isso, é preciso curvála para o outro lado, ou seja, transformar a realidade na qual se está imerso, pensar a educação de um modo diferente.

\section{BIOGRAFIA}

Dermeval está com setenta e cinco anos. Nasceu numa fazenda de Santo Antônio da Posse, no dia 25 de dezembro de 1943, na comarca de Mogi Mirim, no interior de São Paulo. Entretanto, foi registrado em 03 de fevereiro de 1944. Filho de trabalhadores rurais brasileiros e neto de imigrantes italianos. Em 1948, a família de oito filhos se transferiu para a capital paulista, tornando-se operários trabalhando nas fábricas da cidade. Os pais de Dermeval não tiveram a prática de escolaridade. Mesmo assim eram alfabetizados. Mas, ele foi exceção. Saviani teve a oportunidade de estudar em seminários, em regime de tempo integral. Segundo Batista e Lima (2012, p. 2), estudiosos de Saviani, "teve oportunidade de estudar em seminários, onde realizou seus estudos até o início de sua formação universitária, adquirindo uma formação sólida e de compromisso com os subalternos.

Em 1951 e 1954, Dermeval frequentou o ensino primário em grupo escolar, localizado em um galpão de madeira na periferia de São Paulo. Em 1954, iniciou o antigo curso de admissão ginasial, em São Paulo. Mas ainda nesse ano, mudou-se com a família para Cuiabá, onde deu continuidade a seus estudos, cursando o antigo ginásio no Seminário Nossa Senhora da Conceição de 1956 a 1959. Em 1960, fez o curso 
colegial, hoje ensino médio, em Campo Grande, próspera cidade do sul de Mato Grosso, hoje capital de Mato Grosso do Sul. Em 1962, iniciou seus estudos filosóficos no Seminário maior de Aparecida do Norte, em São Paulo. Em 1963, deixa o seminário, depois de muita reflexão, busca de definição de vida com os padres mais experimentados, convencido de que sua opção de vida e trabalho deveriam seguir outro rumo.

Em 1964 volta para a capital paulista. Estando lá, transferiu seu curso de filosofia para a PUC São Paulo, onde o concluiu em 1966. Para prover suas necessidades financeiras e ajudar a família, Dermeval Saviani foi trabalhar no Banco Bandeirantes do Comércio até dezembro de 1975. Ao mesmo tempo prestou concurso público para o Banco do Estado de São Paulo sendo aprovado, o que lhe permitiu cobrir os custos do estudo, transporte, alimentação e ainda ajudar a família.

Em 1967, já como bacharel e licenciado em Filosofia, atuou como professor do Curso de Pedagogia da PUC-SP e lecionou Filosofia e História da Arte num Colégio Estadual, e História e Filosofia da Educação na Escola Normal do Colégio de Sion. Em 1968 deixou o serviço bancário para se dedicar inteiramente ao magistério. Concluiu o doutorado na área de Ciências Humanas: Filosofia da Educação, na Faculdade de Filosofia, Ciência e Letras de São Bento, da PUC-SP. Nessa mesma instituição ajudou a criar o Programa de Mestrado em Filosofia da Educação. Em Batista e Lima (2012, p. 5) lê-se:

Saviani, como estudante da PUC-SP participou da luta estudantil, colocando-se abertamente na defesa do socialismo, estudando e defendendo ideias marxistas. Seus pais e irmãos eram operários, participando ativamente na luta operária, enquanto Saviani participava das lutas estudantis. Esta militância contribuiu para o fortalecimento de convicções sobre a necessidade de transformação da sociedade.

Na PUC-SP, Saviani participou da militância estudantil até a extinção dos órgãos de representação estudantil, em novembro de 1964, já no contexto do Golpe Civil Militar. É importante salientar que a militância de Saviani em nada prejudicou sua dedicação 
aos estudos e trabalhos em disciplinas da graduação. Mesmo na preparação ao doutorado, sem bolsa ou afastamento, sua atenção aos estudos e pesquisas não deixou que relaxasse sua preparação às aulas, correção de trabalhos dos alunos, provas, e ao mesmo tempo, as leituras e escritos da tese, concluída em 1977. Em sua tese de doutorado, intitulada: "Educação Brasileira: estrutura e sistema", Saviani expressa a preocupação por uma educação de qualidade, acessível a todos os indivíduos e garantida a partir de um Sistema Nacional de Educação.

Retroagindo um pouco na trajetória de Saviani, em julho de 1966, quando ainda era estudante do quarto ano de Filosofia, o professor Joel Martins assumiu interinamente a cadeira de Filosofia da Educação para o curso de Pedagogia da PUC-SP e indicou Saviani como monitor, dando, assim, início à sua carreira de professor. Após a defesa de sua tese de doutorado, começou a trabalhar também na PUC-SP como professor de doutorado em Educação. Trabalhou, ainda, na Universidade Federal de São Carlos, no Programa de Pós- Graduação. Aprimorou seus estudos também no exterior: França, Itália e Alemanha. Em 1980 ingressou na UNICAMP onde permanece até hoje como professor colaborador. Consta, em seu currículo, que participou da fundação da ANDES, Associação Nacional da Educação e foi sócio fundador da ANPED, Associação Nacional da Educação e Pesquisas em Educação e do CEDES - Centro de Estudo de Educação e Sociedade.

Em 1986, completou a livre docência na área de História da Educação, na Faculdade de Educação da UNICAMP. Em pleno exercício de sua profissão Saviani não descansou. Ainda em 1986 criou o Grupo de Estudo e Pesquisa de História e Sociedade e Educação no Brasil. Entre 1989 e 1992 coordenou o Programa de PósGraduação da UNICAMP. Considerado filósofo da Educação e/ou Pedagogo da "pedagogia dialética" que denominou "Pedagogia Histórico-Crítica (MARSIGLIA; CURY, 2017). Dermeval casou-se em 1984 e em 1988 teve Benjamim, ao qual devotou um carinho paternal tão intenso quanto sua dedicação ao ensino e produção cientifica-pedagógica. Na edição comemorativa de 25 anos do lançamento do livro "Escola e Democracia", Saviani escreveu a seguinte dedicatória: "Para Benjamim, 
esperando que os filhos de sua geração alcancem estudar numa escola verdadeiramente democrática".

Dermeval estava convencido sobre a necessidade de se elaborar uma proposta pedagógica que fizesse frente às pedagogias conservadoras. Uma espécie de pedagogia "de esquerda", confrontando o pensamento reacionário da educação vigente. A primeira tentativa de sistematização de sua concepção pedagógica ficou expressa num artigo intitulado "Escola Democrática para além da Curvatura da Vara", publicado em 1982 na Revista ANDE n 3. Em 1983 foi lançado o Livro Escola e Democracia e nele foi adicionado esse texto. A partir daí começa a ganhar corpo uma nova pedagogia crítica não-reprodutivista, a pedagogia "Histórico Crítica", como a denominou o próprio Saviani (2008, p. 140-141).

[...] a expressão Histórico-Crítica traduzia de modo pertinente o que estava sendo pensado. Então a expressão "histórico-crítica, de certa forma, contrapunha-se a crítico-reprodutivista. É crítica como esta, mas diferentemente dela não é reprodutivista, mas enraizada na História. Foi assim que surgia a expressão. A partir de 1964 adotei essa nomenclatura para a corrente pedagógica de que venho tentar desenvolver.

Ciente da importância de uma compreensão larga da História da Educação, Saviani pôs-se a elaborar um estudo que reunisse tanto a contribuição dos estudiosos quanto a sua própria. Oferece aos estudantes, docentes e pesquisadores um recurso que lhe permitisse abordar a educação em seu conjunto, desde as origens até nossos dias. Produzindo daí o livro "História das Ideias Pedagógicas no Brasil"[3]. A emergência desta pedagogia histórico-critica nasceu num contexto de forte repressão militar, marcado por ameaças, perseguições, prisões, torturas e pressão militar, assassinatos de lideranças sociais, políticas, religiosas e intelectuais. Foi na luta social contra a repressão militar e seus aspectos educacionais, com as greves trabalhistas, nos sindicatos e nas igrejas que Saviani forjou sua contribuição para a educação brasileira, desenvolvendo uma teoria de educação voltada para a sociedade trabalhadora popular e à classe intelectual. 


\section{OBRAS}

Dermeval Saviani não guarda só para a academia ou para seu saber o que produziu ou adquiriu e aperfeiçoou de outros. Ele é prodigo em sociabilizar o conhecimento e torná-lo público, o que ele angariava pelos seus estudos, leituras, reflexões, congressos, trabalhos de grupo etc. O mecanismo de difusão do conhecimento por ele empregado tomou forma a partir da publicação em livros, revistas, palestras, artigos, seminários, debates e outros mais. Entre os livros publicados mais robustos e dedicados à educação e pedagogia destacam-se:

- "Escola e Democracia". Nele expõe a tentativa de sistematizar sua concepção pedagógica e o saber sistematizado como um instrumento de compreensão da realidade;

- Na mesma linha pedagógica publicou: "História das Ideias Pedagógicas no Brasil". Em seguida "Pedagogia Histórico-Crítica, Primeira Aproximação" e, ainda em 2009, "Educação: Do Senso Comum à Consciência Filosófica". Por fim, em 1984, publicou o "Ensino Público e Algumas Falas Sobre Universidade".

\section{PEDAGOGIA HISTÓRICO-CRÍTICA}

A pedagogia Histórico Crítica, formulada por Dermeval Saviani, surge, no Brasil, como resposta à necessidade de uma teoria da educação que permitisse uma análise crítica da educação a partir da sociedade concreta em que vivemos. É um importante instrumento para provocar o processo de emancipação humana, sobretudo das camadas populares. Oportuniza, ainda mais, uma visão crítica da sociedade capitalista. A Pedagogia Histórico Crítica alinha-se à uma concepção pedagógica transformadora que a coloca em lado oposto às tendências pós-modernistas que levam à desvalorização do saber humano sistematizado. Em Escola e Democracia (2009), Saviani defende o saber sistematizado como um instrumento para a compreensão da realidade. Com este saber, as classes subalternas encontram condições de defesa dos seus interesses. 
A desvalorização dos conteúdos, acreditando na capacidade dos alunos na escolha dos métodos de pesquisa, esvaziaram a escola do método do saber sistematizado. Essa proposta foi lançada como crítica ao método tradicional, argumentando que se tratava de um método científico, dogmático, medieval, como observa Saviani (2009, p. 42): "o ensino tradicional propunha-se a transmitir os conhecimentos obtidos pela ciência, portanto, já compreendidos, sistematizados e incorporados ao acervo cultural da humanidade". A pedagogia histórico-crítica não defende a pedagogia tradicional como a melhor opção para a transformação do ser social, porém, alerta que os métodos escolanovistas se encheram de argumentos atacando uma proposta que, em termos de ordem democrática, mantinha às suas essências em maior condição de levar o sujeito a conhecimento existente e produzido pela humanidade ao longo do tempo, como aludem Batista e Lima (2012).

Saviani ousou, em tempos sombrios da história, apresentar uma proposta pedagógica e educacional que fugiu ao modismo escolanovista e questionou, ao mesmo tempo, as teses pedagógicas conservadoras sem capitular ao reprodutivismo. Nesse contexto, Saviani apresenta, à sociedade, uma teoria crítica da educação, fundamentada no materialismo histórico-dialético. Batista e Lima (2012), analisando a obra de Saviani, destacaram alguns passos para desenvolver a pedagogia histórico crítica, a compreendendo como uma educação revolucionária. Esses passos encontram-se em Saviani (2009, p. 64):

A prática social: ponto de partida da prática educativa, é comum ao professor e a alunos. Leve-se em conta que há uma diferença de compreensão da prática social. A compreensão do professor é sintética e implica certa articulação dos conhecimentos e experiências.

Problematização: é a diretriz dos conteúdos que serão trabalhados, identificação dos principais problemas da prática social. Em consequência, que conhecimento é necessário dominar. 
Instrumentalização: trata-se de apropriar-se dos instrumentos teóricos e práticos necessários para superar os problemas detectados na prática social.

Catarse: é uma concepção gramisciana de elaboração superior da estrutura sem superestrutura na convivência humana. Adquirir os instrumentos básicos: é chegado o momento de uma expressão mais elaborada de entender a prática social.

Prática Social: ponto de chegada da prática educativa, distante da prática social da qual se partiu, o caminho percorrido possibilitou ao professor conduzir 0 aluno ao ponto de problematização e instrumentalização em que ele próprio se encontra na abordagem dos conteúdos. O método se transforma em prática.

Entende-se que o método torna-se, então, uma prática que deve sustentar a transformação do próprio professor enquanto o conteúdo, por sua vez, deve incorporar-se à prática social do aluno, distante agora do senso comum, alimentado pela consciência filosófica. No dizer de Saviani (2009, p. 65):

Nesse ponto, ao mesmo tempo que os alunos ascendem ao nível sintético em que, por supor, já se sabe-se encontrava o professor no ponto de partida, reduz a precariedade da síntese do professor, cuja compreensão se tona mais e mais orgânica. Essa elaboração ao nível do professor é essencial para compreender-se a especificidade da relação pedagógica. Daí por que o momento catártico pode ser considerado o ponto culminante do processo educativo, já que aí se realiza, pela mediação da análise levado a cabo no processo de ensino, a passagem da síncrese à síntese.

Por aí, Saviani se revela um pesquisador filosófico ligado à Educação trabalhando um conjunto que se completa num pensamento social, com as lutas sociais e sempre na defesa de uma sociedade justa e igualitária. Desde 1984, Dermeval Saviani vem 
desenvolvendo uma modalidade nova de Pedagogia: a "Pedagogia Histórico-Crítica". Não satisfeito com as pedagogias não críticas, como a tradição vem com propostas de uma pedagogia nova, representada pelo "escolanovismo", pela pedagogia tecnicista e pelas teorias crítico-reprodutivistas, Saviani cria uma pedagogia mais completa, mais atual, mais compreensiva, totalizante ao que ele denomina "Pedagogia Histórico-Crítica". Em sua obra "Escola e Democracia" encontra-se uma introdução à essa pedagogia. Nesse livro, Saviani já esboça algumas linhas condutoras de sua nova proposta pedagógica.

Já no primeiro capítulo apresenta uma síntese das principais teorias da educação, abrangendo as teorias não críticas (pedagogia tradicional, pedagogia nova e pedagogia tecnicista) e as teorias críticas reprodutivistas (teoria da escola enquanto violência simbólica, teoria da escola como aparelho ideológico do Estado e teoria de escola dualista. Essas teorias já se representaram como algo a caminho da superação e a necessidade de uma proposta por uma teoria crítica da educação que será a pedagogia aqui elencada. Em um segundo capítulo da obra Escola e Democracia, Saviani retoma de Lenin a chamada "Teoria da Curvatura da Vara". Ao ser criticado por assumir posições extremistas radicais, adota a própria explicação de Lenin sobre esta teoria: "quando a vara está torta, ela fica curva de um lado e se você quiser endireitá-la, não basta colocá-la na posição correta. É preciso curvá-la para o lado oposto" (SAVIANI, 2009, pp. 64-65).

Essa tese foi colocada por Lenin ao ser criticado por assumir posições extremistas e radicais. Dermeval aplica a si mesmo essa experiência conflitante ao apresentar sua versão sobre a necessidade de uma pedagogia histórica e crítica. Contrapõe-se ao dilema entre educação velha e educação nova, pedagogia nova e pedagogia velha, e, assim, posiciona-se quanto ao caráter revolucionário da pedagogia da essência: e do caráter reacionário da pedagogia da existência. De outro lado, a pedagogia da essência também tem um papel revolucionário, pois, ao defender a igualdade essencial entre os homens, privilegia-se a eliminação dos privilégios que impedem a realização de parcela considerável dos homens. Saviani vai além da teoria da curvatura da vara, portanto. 
Ele tenta derrubar o ideário escolanovista que se transformou em senso comum para os educadores e tornou forma de se conceber a educação. O objetivo de Dermeval é tentar reverter a tendência dominante. Ao contrário do que era corrente na cabeça do educador, o tradicionalismo, que considera a pedagogia nova como portadora de todas as virtudes e nenhum vício, atribuindo, inversamente à pedagogia tradicional, todos os vícios e nenhuma virtude, Saviani empenhou-se em demonstrar o inverso. Faz, então, um estudo sintetizado sobre três teses. A primeira tese (filosóficohistórica) abrange o caráter revolucionário da pedagogia da essência (pedagogia/tradicional) e do caráter reacionário da pedagogia da existência (pedagogia nova). A segunda tese (pedagógico-metodológica) dispõe sobre o método tradicional de caráter científico.

A terceira tese (especificamente política), visa refletir sobre a temática da democracia no interior da escola, sobretudo o que tange a construção de uma ordem democrática, parte-se do princípio de que é preciso dar vida à democracia, pois tende a ser silenciada (SAVIANI, 2004). Assim se explica a expressão teoria da curvatura da vara: para endireitar uma vara que se encontra torta, não basta colocá-la na posição correta, mas é necessário curvá-la do lado oposto. Isso ocorre também no debate ideológico: não basta ensinar a concepção correta para que os desvios sejam corrigidos, é necessário abalar as certezas, desautorizar o senso comum. A pedagogia revolucionária e crítica, longe de entender a educação como determinante principal das transformações sociais, reconhece ser ela elemento secundário na pedagogia da essência e do existencialismo. A educação, portanto, não transforma de modo direto e imediato e sim de modo indireto, isto é, agindo-se sobre os sujeitos da prática. Como diz Vásquez (1968, pp. 206-207):

A teoria em si não transforma o mundo. Pode contribuir para a sua transformação, mas para isso tem que sair de si mesmo, em primeiro lugar tem que ser assimilada pelos que vão ocasionar, com seus atos reais efetivos, tal transformação. Entre a teoria e a atividade prática transformadora se tem sempre um trabalho de educação da consciência. 
Daí é fácil identificar o entendimento da educação como mediadora no seio da prática social. E, se a educação é mediação, isto significa que ela não se justifica por si mesma, mas tem sua razão de ser nos efeitos que se prolongam para além dela e que persistem mesmo após a cessação da ação pedagógica, como conclui Saviani. Ele é um eterno insatisfeito quanto às reflexões e achados sobre as formas de evolução do conceito e da prática educativa. Depois de explorar a extensão da atuação das bases das pedagogias não-críticas (pedagogia tradicional, pedagogia nova e pedagogia tecnicista); das teorias crítico-reprodutivistas (teoria da escola como violência simbólica); da teoria da escola enquanto aparelho ideológico do estado e da teoria dialética, Saviani tentou superar tais teorias e enunciou acerca da teoria crítica da educação ou "pedagogia-histórico-crítica".

Compreender a questão educacional a partir do desenvolvimento histórico foi o seu objetivo. A partir de 1978, passou-se a compreender a questão educacional a partir dos condicionamentos sociais. Depreende-se que educação é influenciada pela sociedade que, por sua vez, é influenciada pela educação. Há uma relação recíproca entre educação e sociedade. Em suma: a educação interfere na sociedade, podendo contribuir para sua própria transformação. Esta passagem da visão crítica à histórica para uma visão crítico-dialética, portanto, histórico-crítica, é o que Saviani traduz como pedagogia histórico-crítica.

Defende, então, a partir dessa nova ótica atinente à educação, que o ser humano é um ser natural peculiar, distinto dos demais seres naturais. Enquanto esses sobrevivem, adaptando-se à natureza que provê suas condições de existência, o homem precisa adaptar a natureza a si, tirando dela o necessário para sua existência. Daí provém a especificidade desse animal, chamado homem. Para sobreviver, ele precisa estar em comunhão com a natureza, transformando-a. O ser humano se faz atuando sobre a natureza pelo trabalho. E transformando a natureza, ele mesmo se transforma.

O que se chama desenvolvimento histórico, é o processo através do qual o ser humano produz a sua existência no tempo. Agindo sobre a natureza, ou seja, trabalhando, o homem vai construindo o mundo 
histórico. Vai construindo o mundo humano! $\mathrm{E}$ a educação tem sua origem nesse processo (SAVIANI, 2011, p. 81).

A pedagogia histórico-crítica teve suas raízes no movimento de maio de 1968, a chamada revolução cultural dos jovens, eclodida principalmente na França, mas que se espalhou por diversos países, inclusive no Brasil. Esse movimento pretendia realizar a revolução social pela revolução cultural. Mudar as bases da sociedade pela revolução educacional, abrangendo não apenas a escola, mas todo o ambiente cultural, era um dos objetivos. Esta visão crítica, embora ainda reprodutivista, desempenhou um papel importante, porque, de alguma forma, impulsionou a crítica ao regime autoritário e à pedagogia autoritária vigente naquele regime. De certa forma, como observa Saviani, estas teorias alimentaram as reflexões e as análises daqueles que, em nosso país, posicionaram-se contra a pedagogia oficial e dominante.

Entretanto, essa pedagogia crítica ainda embrionária se revela capaz de fazer a crítica do existente, de explicitar os mecanismos do existente, mas não tem pressuposto de intervenção prática. Limita-se a constatar que é assim e não pode ser de outro modo, mas, o problema é que a questão central era justamente como atuar de modo crítico no campo pedagógico como, por exemplo, no ato de agir e no desenvolvimento de uma prática de caráter crítico. Nesse contexto, almejou-se a formulação de uma proposta que superasse esta visão crítico-reprodutivista, o que culminou o surgimento da pedagogia aqui abordada. A pedagogia histórico-crítica implica os determinantes sociais da educação, a compreensão do grau em que as contradições da sociedade marcam a educação e o posicionamento diante de tais contradições.

\section{CONSIDERAÇÕES FINAIS}

Em síntese, procuramos traçar o histórico de Dermeval Saviani, um educador que provocou no seu tempo grande reflexão sobre o modelo educacional vigente e que ainda provoca na atualidade um novo pensamento para a educação brasileira, afinal, vive-se dias de grande curvatura da vara e ela se manifesta por meio dos modelos educacionais que, pouco a pouco, vão sendo impostos, tais como Escola Sem Partido, 
entre outros. Como educador e crítico por vocação, esta expressa como professor, animador e escritor educacional totalmente devotado à educação, condizente com as necessidades de seu tempo e dos tempos futuros, o autor abordou de forma atualizada e libertadora lucidez no que tange à educação crítica.

Este é Dermeval Saviani, alguém que a partir de seu legado, deixa a todos os educadores e educadoras uma forte provocação e, ao mesmo tempo, um forte senso de inquietude frente aos modelos educacionais tradicionais vigentes em nosso país, o que motiva o confronto e não aceitação passiva desses métodos. Sim, é preciso refletir e, ao refletir, tomar consciência do sistema no qual o educador (a) se encontra. E, ao tomar consciência, deve-se buscar a mudança, esta que se dá a partir do modelo pedagógico histórico-crítico. Por fim, esperamos que o presente artigo tenha atingido o seu objetivo, o ser luz em meio a escuridão, e provocador de reflexão em meio à acomodação e confusão.

\section{REFERÊNCIAS}

BATISTA, E. L.; LIMA, M. R. Dermeval Saviani-uma trajetória de luta e compromisso com a educação transformadora. Germinal: Marxismo e Educação em Debate, v. 5, n. 2, p. 203-215, 2013.

MARSIGLIA, A. C. G.; CURY, C. R. J. Dermeval Saviani: uma trajetória cinquentenária. Interface, v. 21, n. 62, p. 497-507, 2017.

SAVIANI, D. História das ideias pedagógicas no Brasil. Campinas: Autores Associados, 2007.

SAVIANI, D. Pedagogia histórico-crítica: primeiras aproximações. $10^{\mathrm{a}} \mathrm{ed}$. Campinas: Autores Associados, 2008.

SAVIANI, D. Educação: do senso comum à consciência filosófica. $18^{\mathrm{a}}$ ed. Campinas: Autores Associados, 2009.

SAVIANI, D. Escola e democracia. 41를 ed. Campinas: Autores Associados, 2009. 
VÁSQUES, A. S. Filosofia da práxis. Rio de Janeiro: Paz e Terra, 1968.

\section{APÊNDICE - REFERÊNCIA DE NOTA DE RODAPÉ}

3. 'História das Ideias Pedagógicas é um compêndio sobre a história da educação. Dermeval Saviani divide a obra em quatro partes - 1. As ideias pedagógicas no Brasil entre 1549 e 1759 - monopólio da vertente religiosa da pedagogia tradicional; 2. 1759 a 1932 - coexistência entre as vertentes religiosa e leiga da pedagogia tradicional; 3. 1932 a 1969 - predomínio da pedagogia nova; e 4. 1969 a 2001 - configuração da concepção de pedagogia produtivista.

Enviado: Fevereiro, 2020.

Aprovado: Maio, 2020. 